\title{
Regulation of Bud Dormancy and Bud Break in Japanese Apricot (Prunus mume Siebold \& Zucc.) and Peach [Prunus persica (L.) Batsch]: A Summary of Recent Studies
}

\author{
Hisayo Yamane \\ Graduate School of Agriculture, Kyoto University, Kyoto 606-8502, Japan
}

\begin{abstract}
Bud dormancy allows most deciduous fruit tree species to avoid injury in unsuitable environments, synchronize their annual growth, and adapt to a temperate zone climate. Because bud dormancy affects next season's fruit production and vegetative growth, it is considered one of the most important physiological factors that control fruit production. Recent global climate changes require us to better understand the genetic factors regulating bud dormancy, especially those that induce dormancy release and subsequent bud break. In this review, environmental factors that affect the seasonal dormancy depth of Japanese apricot ( $P$. mume Siebold \& Zucc.) and peach $[P$. persica (L.) Batsch] are first outlined. Next, recent progress of genetic, biochemical, and molecular biological studies of Prunus dormancy regulation is described. Recent advances in functional genomics have promoted the discovery of gene function and gene networks associated with bud dormancy regulation. A group of candidate genes for bud dormancy regulation, the DORMANCY-ASSOCIATED MADS-box (DAM) genes in Prunus, are focused. Recently reported expressional analysis suggests a significant role for $D A M$ s in dormancy release and bud break of Japanese apricot and peach vegetative buds. Transformation studies of PmDAM6 have demonstrated that it has an inhibitory effect on the apical growth of poplar (Populus spp.). As bud dormancy is a quantitative polygenic trait, not only $D A M$ s, but also other genes and gene networks appear to regulate bud dormancy. Ongoing and future studies will undoubtedly facilitate the unveiling of the molecular aspects of bud dormancy regulation in temperate fruit tree species of Prunus.
\end{abstract}

Key Words: chilling requirement, climate change, DORMANCY-ASSOCIATED MADS-box, endodormancy, transcription factor.

\section{Introduction}

Various horticulturally important fruit tree species belong to the Prunus genus of Rosaceae, including peach (Prunus persica), apricot (P. armeniaca), plum (P. salicina, P. domestica), Japanese apricot (P. mume), cherry (P. avium, P. cerasus), and almond (P. dulcis). As with other perennial woody plants cultivated in temperate zones, these species synchronize their annual

Received; November 28, 2013. Accepted; March 10, 2014.

First Published Online in J-STAGE on May 1, 2014.

The studies on Japanese apricot vegetative bud dormancy described in this review were conducted by the author's research group and financially supported by the Program for the Promotion of Basic and Applied Research for Innovation in Bio-oriented Industry from the Bio-oriented Technology Research Advancement Institution (BRAIN), Japan and by the Japan Society for the Promotion of Science (Grant-inAid KAKENHI No. 23380017).

E-mail: hyamane@kais.kyoto-u.ac.jp. growth patterns with seasonal environmental changes. This allows plants to avoid injury from environmental stresses such as cold in the winter. Dormancy is one of the controlling mechanisms that enable woody perennials to adapt to seasonal environmental changes. Dormancy is an agronomically important trait because it influences fruit production by promoting survival in an unfavorable environment, and ensures simultaneous blooming in the orchard. As a result, dormancy has an impact upon the following season's fruit production and vegetative growth. Recent global climate changes such as global warming (Solomon, 2007) are reported to affect winter chilling accumulation (Atkinson et al., 2013; Luedeling et al., 2011) and the dormancy release of fruit trees (Sugiura et al., 2007). Therefore, it is necessary to investigate the genetic factors underlying the control of dormancy to secure sustainable fruit production and maintain supply (Campoy et al., 2011a).

Bud dormancy can be defined as the inability of a 
meristem to resume growth under favorable conditions (Rohde and Bhalerao, 2007). Lang (1987) and Lang et al. (1987) classified the dormancy states as being paradormancy, endodormancy, and ecodormancy. Both endodormancy and paradormancy can be defined as a state induced by the perception of the promoting environmental or endogenous signaling cue, whether this originated solely within the meristem-containing tissue (endodormant) or in a structure distinct from the structure undergoing dormancy (paradormant). A specific amount of chilling exposure is known to critically induce the shift of endodormancy to ecodormancy. Ecodormancy is a state brought about by the limitation of growth-promoting factors, such as warm temperatures, sufficient water and nutrient supply. Although Lang's definition has been widely adopted for use in dormancy research papers, recently accumulated knowledge about the molecular mechanisms of dormancy requires us to revisit the use of this terminology. For example, it is difficult to discriminate between paradormancy and endodormancy if the involvement of a mobile signal from leaves to meristem is critical for meristem endodormancy regulation. Furthermore, since chilling exposure can promote bud burst even after endodormancy release, the timing of chilling requirement (CR) fulfillment is difficult to determine. Therefore, it is difficult to distinguish between endodormant buds and ecodormant buds. Indeed, bud dormancy is a dynamic rather than a single state, with interactions between genetic and environmental cues (as reviewed by Cooke et al., 2012). Therefore this review uses the terms deep dormancy, non-deep dormancy, and less dormancy, as proposed by Cooke et al. (2012), where the number of opened buds increases and time to bud burst shortens as the tree phase moves from deep-dormant state to less-dormant state.

Genetic and molecular regulation of bud dormancy has been extensively studied in a model woody plant, poplar (Populus spp.), and much progress has been made, as reviewed by Cooke et al. (2012), Rinne et al. (2010), and Rohde and Bhalerao (2007). In Populus, the photoperiodic control of growth cessation and bud set has been extensively studied as target dormancy traits compared to other dormancy events, such as dormancy maintenance and release. The accumulated evidence suggested that phytochrome- and circadian clock-related genes such as PHYTOCHROME A, LATE ELONGATED HYPOCOTYL, CIRCADIAN CLOCK ASSOCIATED 1, and TIMING OF CAB EXPRESSION were involved in short daylength (SD)-induced bud set in poplar (Ibáñez et al., 2010; Kozarewa et al., 2010; Olsen et al., 1997; Ruttink et al., 2007). An important breakthrough in our understanding of poplar growth cessation and bud set was the finding that the CONSTANS (CO)/FT module, a well-known component playing a critical role in flowering induction, also regulates this SD-induced phase transition (Böhlenius et al., 2006; Hsu et al., 2011; Pin and Nilsson, 2012). Rohde et al. (2011) identified six robust QTLs for time to bud set conserved in four different poplar pedigrees, and $F T$ was co-localized with one of these QTLs. Recently, Rinne et al. (2011) reported that $F T$ is hyperinduced during the chilling-induced dormancy release of poplar, suggesting that $F T$ is involved not only in dormancy induction but also in dormancy release. Mohamed et al. (2010) reported that overexpression of CENTRORADIALIS (CEN)/TERMINAL FLOWER1 (TFL1), another member of the PEBP family to which $F T$ belongs, resulted in altered chilling requirements and delayed bud burst in Populus. As with seed dormancy regulation (for a review, see Finkelstein et al., 2008), plant hormones such as abscisic acid (ABA) and gibberellic acid (GA) seem to be integrated in bud dormancy regulation (Cooke et al., 2012). For example, Rinne et al. (2011) reported that chilling upregulated a number of GA biosynthesis genes, leading to reopened signaling conduits in the embryonic shoot and resulting in dormancy release. A gene encoding transcription factor involved in ABA signaling, ABSCISIC ACID-INSENSITIVE3, overexpressors showed altered bud formation (Rohde et al., 2002). In addition, a recent work has highlighted the potential importance of epigenetic regulation in bud dormancy of Populus (Bräutigam et al., 2013; Ruttink et al., 2007).

The accumulated knowledge about poplar bud dormancy regulation, as briefly described above, is of great use and undoubtedly accelerates molecular and genomic efforts to discover the genes associated with the bud dormancy of temperate fruit trees. However, we must keep in mind that programmed genetic systems of bud dormancy regulation may not necessarily be the same among the diverse plant species that exhibit bud dormancy, even though most perennial woody plants have adapted and evolved dormancy for survival. In addition, primary environmental cues that trigger the bud phenology cycle, such as the induction of bud set (or shoot tip abortion), vary depending on a given plant species (Tanino et al., 2010). Accordingly, the characterization of molecular networks regulating the dormancy of various woody species is being carried out by omics studies that use the target plants themselves. Examples of recently published omics studies using agronomically important fruit tree species include: grapevine (Vitis spp.) (Diaz-Riquelme et al., 2012; Mathiason et al., 2009); Japanese pear (Pyrus pyrifolia) (Bai et al., 2013; Liu et al., 2012; Nishitani et al., 2012); chestnut (Castanea sativa) (Santamaría et al., 2011); raspberry (Rubus idaeus) (Mazzitelli et al., 2007); blackcurrant (Ribes nigrum L.) (Hedley et al., 2010); and Prunus spp. (described in detail below).

This review focuses on the molecular mechanisms of the regulation of bud dormancy release of fruit tree species of Prunus, such as peach and Japanese apricot. The review first describes the growth-dormancy cycle of fruit tree species of Prunus, and environmental cues related to bud phenological changes are presented. Then, the recent progress of genetic and molecular approaches 
used to understand the regulation of bud dormancy release in Prunus are outlined. Identification and characterization of Prunus MADS-box genes, candidate genes that may play roles in regulating Prunus bud dormancy, are highlighted. Finally, the current working hypothesis of the biological function of these genes is discussed based on data obtained from our transgenic and other reported studies.

\section{Seasonal growth-dormancy phase transition of Japanese apricot and peach in the context of environmental changes}

A typical Japanese apricot leaf axil has three separate buds, and these consist of a single vegetative bud subtended by two flower buds. The vegetative bud contains a shoot apical meristem, and this generates an annual shoot for the next growing season, whereas each flower bud contains a floral meristem, which develops into a solitary flower. Following floral meristem formation in early summer, blooming is not usually observed until the next spring, after the passing of winter. Thus, flower buds stay in a dormant state during autumn and winter; however, flower organ differentiation continues during this dormant period (Takamatsu et al., 2004). Continuous flower organ differentiation and development during dormancy are also observed in peach (Yamane, 2013; Yamane et al., 2011b, c). Flower bud development and dormancy are more directly related to fruit production than vegetative (leaf) bud dormancy, and its understanding is therefore of more interest for agriculture use. However, this review mainly focuses on the dormancy of vegetative growth because the shoot apical meristem has been an exclusive target of dormancy studies for many other perennial plants, including poplar. In major fruit tree species other than Prunus spp., such as apple, Japanese pear, persimmon, and grape, which normally bear mixed buds, floral buds are often used as materials for bud dormancy studies, this is because these buds contain both the floral meristem and the shoot apical meristem within a single bud. As both flower and vegetative buds commonly require chilling exposure for bud break, knowledge of vegetative bud dormancy regulation would be helpful for understanding flower bud dormancy in Prunus.

The seasonal phase transition from active vegetative growth to dormancy in Japanese apricot occurs gradually, and as with other temperate fruit trees, takes a long time. Figure 1 shows a schematic of the annual growth-dormancy phase transition and seasonal vegetative and reproductive development of Japanese apricot. Although blooming is often observed from February to March under field conditions in Kyoto, vegetative bud flushing does not occur until April. Shoot growth cessation of long branches is observed from June, a second flushing sometimes follows, and the majority of long branches have stopped active growth by the end of August. The trees shed their leaves by early December.

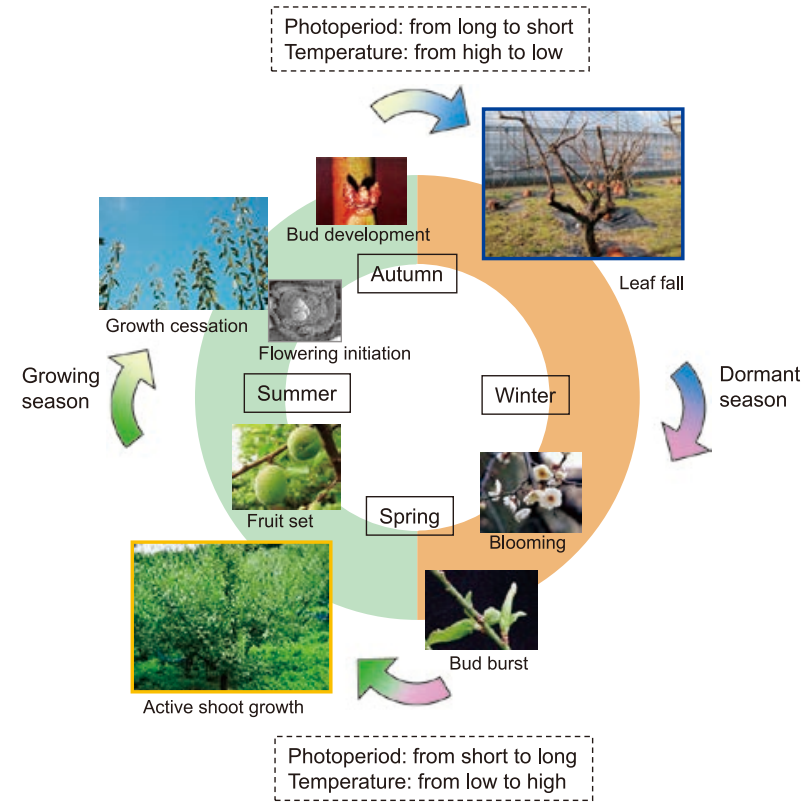

Fig. 1. Schematic of phenology and annual growth-dormancy phase transition of Japanese apricot.

Heide (2008) investigated the effects of temperature and photoperiod on the growth and growth cessation of three Prunus spp., sour cherry (P. cerasus), Insititia plum (P. insititia), and sweet cherry (P. avium L.). Their results demonstrated that there was a pronounced interaction of photoperiod and temperature in the regulation of growth and growth cessation in all three species. On the other hand, apple and pear tended to show continuous growth regardless of photoperiodic conditions and dormancy of these species was induced by lowering the temperature (Heide and Prestrud, 2005). Vegetative growth patterns of Japanese apricot adult trees grown under field conditions suggested that growth cessation of Japanese apricot appeared to respond to the progressively decreasing photoperiod and was further established by lowering temperatures. However, continuous growth was not achieved in controlled long day length and warm temperature conditions in Prunus (Kataoka et al., 2002; Samish, 1954); thus, it is proposed that an endogenous mechanism induces growth cessation and environmental factors modulate it.

Seasonal changes of the dormancy level in given genotypes can be measured using repeated sampling of cuttings from trees (Gariglio et al., 2006), or using multiple pot-grown trees (Sugiura et al., 2010). Schematics of the experimental procedures used for estimating dormancy levels are shown in Figure 2A. Either branch cuttings, single node cuttings, or pot-grown trees are incubated under forcing conditions (long daylength, with an optimum temperature of approximately $20-25^{\circ} \mathrm{C}$ ) and the time to bud burst, or the bud burst percentage after a certain period, is measured. Another method of measurement is the comparison of the weight of buds before and after cuttings are exposed to a forcing condition for a 
A. Experiments for estimating dormant depth of buds

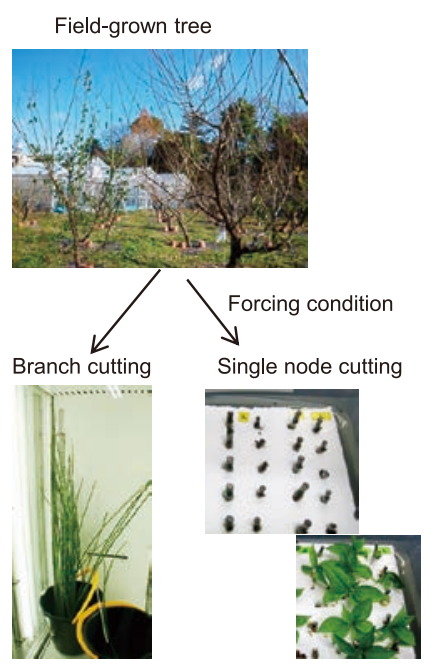

Pot-grown tree in field
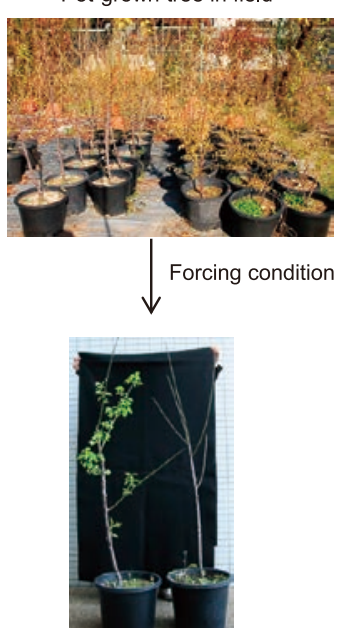

B. Experiments for estimating CR

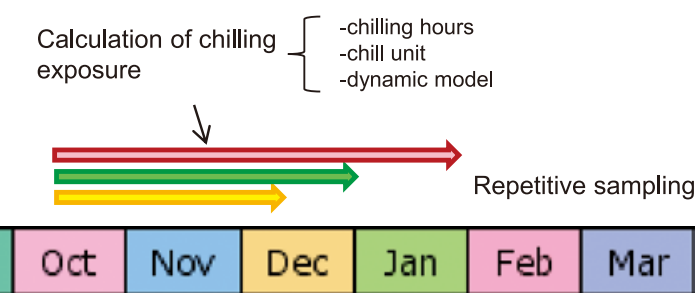

Forcing condition

Counting time to bud burst or bud burst percentage after a certain period of forcing

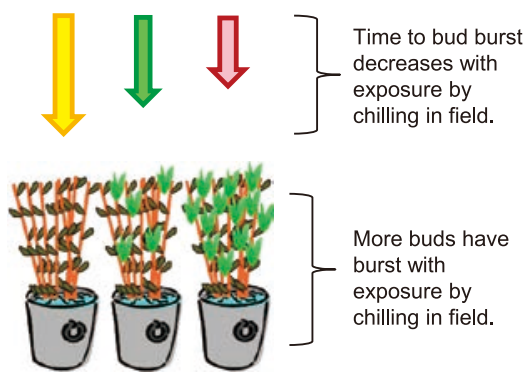

Fig. 2. Schematic of experimental procedures used for estimating dormant depth of buds (A) and CR (B). (A) Branch cutting, single node cutting, or pot-grown trees were used as the experimental materials for estimating dormant levels. (B) CR fulfillment is often determined using the following parameters: bud burst percentage after a certain period of time or decreasing rate of time to bud burst in forcing conditions. Daily accumulation of chilling is calculated by three different models: chilling hours (Weinberger, 1950), chill unit (Richardson et al., 1974), or the dynamic model (Fishman et al., 1987a, b).

predetermined period. The assignment of $\mathrm{CR}$ to a given genotype is based on the accumulated chilling exposure, at the date of forcing treatment when bud burst is observed beyond a predetermined threshold level [(endo) dormancy release date] (Fig. 2B). Typically, three models are used for the calculation of accumulated chilling exposure: the "chill hour model" involves counting the number of hours at temperatures less than $7.2^{\circ} \mathrm{C}\left(45^{\circ} \mathrm{F}\right)$ (Weinberger, 1950); the "chill unit model" considers negative effects of high $\left(>16^{\circ} \mathrm{C}\right)$ and extremely low $\left(<0^{\circ} \mathrm{C}\right)$ temperatures (Richardson et al., 1974) on the fulfillment of $\mathrm{CR}$; and the "dynamic model" considers the effect of different temperature cycles by assuming the conceptual reversible and irreversible portions (chill portions) required to be accumulated for fulfillment of CR (Fishman et al., 1987a, b). It is empirically assumed that the "dynamic model" is the best method to compare CR among different genotypes, especially those cultivated in warm winter climates (Topp et al., 2008). For Japanese apricot grown in a warm climate in Nanjing, China, the dynamic model proved to be the best of the three models for determining cultivar-dependent CR (Gao et al., 2012). This suggests that temperature sensitivity and the associated signal transduction system that leads to dormancy release is more complicated and dynamic than simple memorization of the cold accumulation experienced. Two separate temperature responses are known to lead to bud break, CR and heat requirement, and it is difficult to differentiate them as one can interfere with the other (Erez, 2000; Harrington et al., 2010). Indeed, when buds were exposed to greater chilling, they required less heat accumulation for bud break to occur; therefore, greater heat accumulation can compensate for insufficient chilling. Therefore, it is quite complicated and difficult to accurately quantify chilling and heat requirements. In Japan, the "developmental index (DVI) model" is often used to predict the rate of chilling exposure, namely dormancy progression and release (Sugiura and Honjo, 1997). DVI is set to zero when chilling exposure begins, and reaches $\mathrm{DVI}=1$ when CR is fulfilled. The DVI value is a very useful dormancy parameter because DVI values are assigned based on the tree's temperature response and can be considered as a parameter of the dormancy state at a specific time point from the deep-dormancy state until bud break and blooming (Sugiura and Honjo, 1997). Not only temperature, but daylength, water status, and other uncharacterized factors may affect bud break through, at least partly, enhancing dormancy release in parallel with temperature effects (Erez, 2000; Erez et al., 1998).

In Japanese apricot 'Nanko', seasonal changes of the bud dormancy depth in the Kyoto climate were measured by the cutting method over several different seasons. Figure 3 shows the seasonal changes of bud development and dormancy depth along with annual changes in temperature and daylength. When branches cut from trees were incubated in forcing conditions, bud burst was observed in long branches collected in early June. Bud burst then became unstable, and fluctuated depending on the branches and the year collected after late June, and during summer. This suggests that these buds are facultatively non-deep dormant (Yamane et al., 2008). In fact, a second flushing of 'Nanko' trees under field conditions during summer suggested that they are not completely 


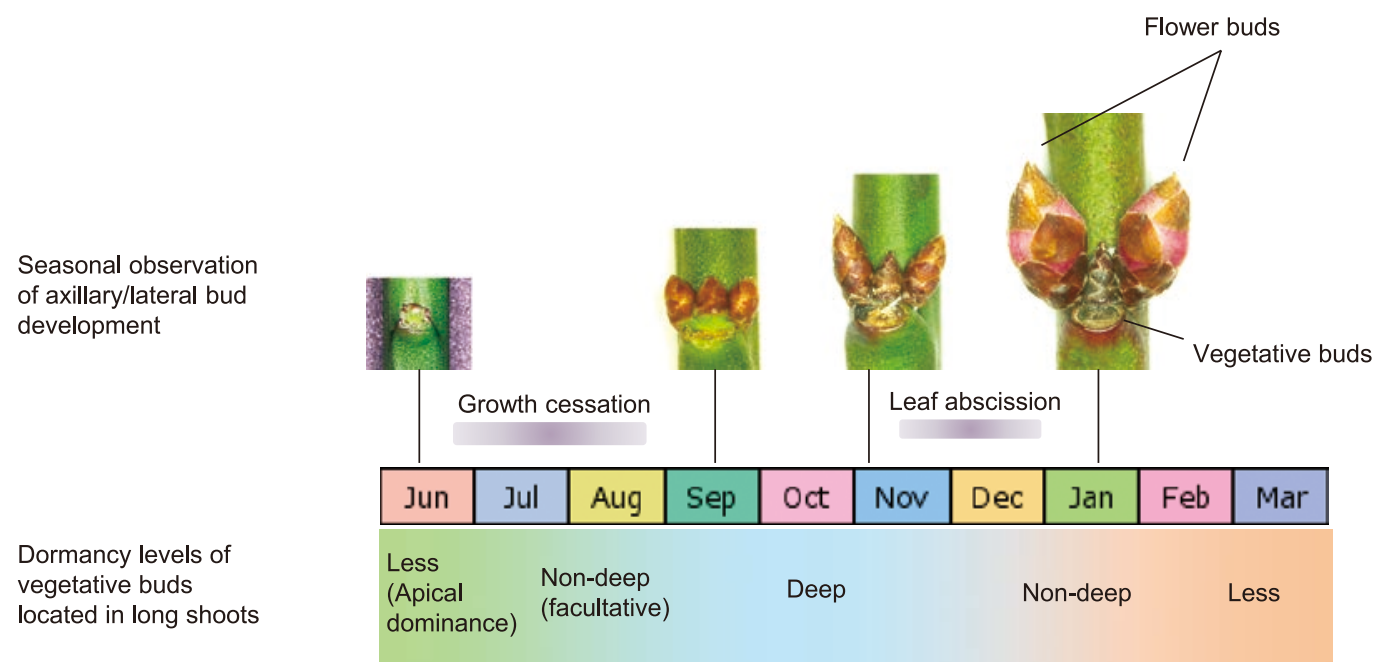

Annual daylength changes (Kyoto, Japan, 2012-2013)

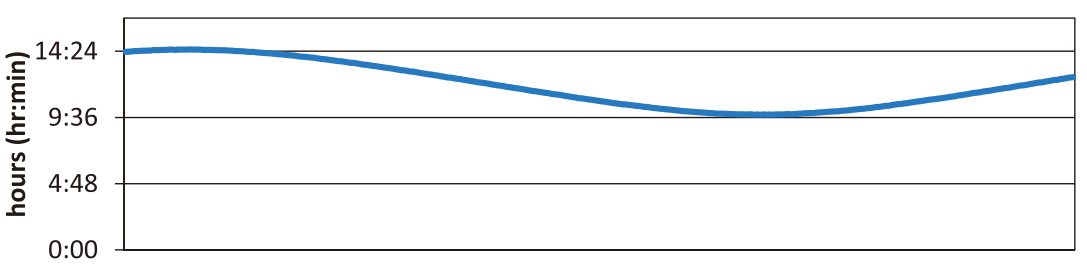

Monthly average temperature (Kyoto, Japan, 2012-2013)

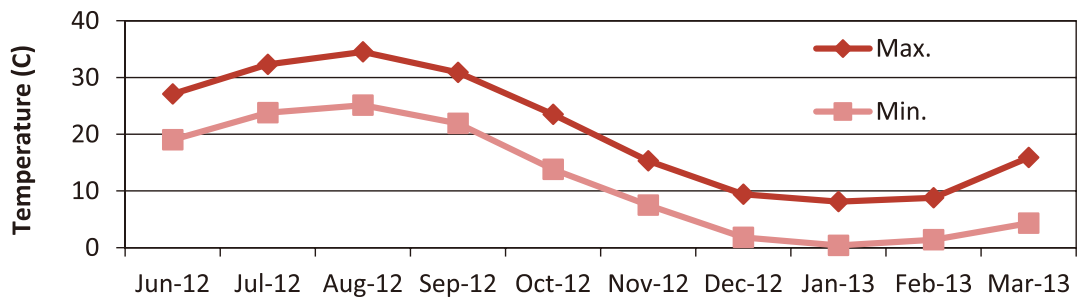

Fig. 3. The seasonal changes of axillary/lateral bud development and dormancy depth of Japanese apricot 'Nanko' grown in Kyoto, Japan. Dormancy depth was estimated by repetitive sampling over several years. As a reference, the information on annual daylength changes and annual average temperature changes in Kyoto (June 2012-March 2013) was downloaded from the National Astronomical Observatory of Japan (http://eco.mtk.nao.ac.jp/koyomi/dni/) and the Japan Meteorological Agency website (http://www.jma.go.jp/jma/index.html), respectively.

dormant. However, bud burst has never been observed in the long branches collected in autumn under any of our forcing conditions (Sasaki et al., 2011; Yamane et al., 2008), suggesting that these buds are deep dormant. Until the cessation of shoot growth, axillary buds were unable to grow due to apical dominance; however, after cessation of growth until leaf abscission, axillary buds were dormant through correlative inhibition, internal inhibitory factors within the bud itself, or both. According to the review by Erez (2000), the inhibitory effects of bud break of axillary or lateral buds start from outside organs such as the leaves, and then gradually change to come from the bud itself, and this shift is believed to be modulated by low temperature (Crabbé, 1994; Faust et al., 1997) and short daylength (Nitsch, 1957).

The effects of chilling deprivation on dormancy release and bud break were tested using pot-grown trees that were defoliated and transferred to the greenhouse $\left(20^{\circ} \mathrm{C}-28^{\circ} \mathrm{C}\right.$, natural daylength, Kyoto climate) in autumn. Bud outgrowth did not resume during the period of observation (Oct. to the following Aug.), and most buds aborted. These results suggested that the dormancy of Japanese apricot can be maintained if chilling exposure is avoided, and that long photoperiods and warm temperature cannot compensate for this completely. Again, chilling exposure seems to be one of the essential factors that lead dormant buds to be released. In the case of pot-grown peach trees, bud break was observed in a few vegetative buds in April following cold deprivation during winter, suggesting that a long photoperiod itself and/or other factors can partly break peach dormancy (H. Yamane, unpublished data).

After passing through autumn, bud burst in forcing conditions using single node cuttings was seen to occur shortly after leaf abscission in mid-December. When a whole branch cutting approach was used, bud burst was observed after January, suggesting that dormancy is released during late December to January, and that 'Nanko' trees are non-deep dormant during these months. However, the bud-burst percentage continues to increase and time to bud burst continues to decrease under forcing conditions from January onwards. Thus, February to 
March are considered to be less dormant. The average air temperature is normally lower in February than January, and additional chilling exposure seems to raise the budbreak frequency after the fulfillment of CR. This hypothesis is supported by other reported chilling treatment experiments (Sasaki et al., 2011; Yamane et al., 2008). Indeed, other factors, such as increasing daylength from January onwards, also seem to induce bud break, as experimentally demonstrated in peach (Erez et al., 1966). Although dormancy is released during January, active vegetative growth in the field does not occur until April. This suggests that heat accumulation or a longer daylength after dormancy release is required for bud flushing in the field, as is observed with other temperate fruit tree species.

\section{Genetic approaches for Prunus dormancy study}

Among the different dormancy events, dormancy release and CR are the most important factors for fruit production; therefore, most genetic, biochemical, and molecular studies have focused on these dormancy events. It is well known that the CR differs among species and cultivars (genotypes) (Westwood, 1993). In peach, a systematic breeding program to create cultivars adapted to subtropical climates began in 1907 in the USA (Topp et al., 2008). This has led many low-chill cultivars with commercially acceptable fruit quality to be released. To date, peach cultivars with CRs ranging from less than 50 chill units (CU) to over $1000 \mathrm{CU}$ have been developed and used for cultivation and breeding worldwide. For Japanese apricot, low-chill lines and evergreen-like lines have been found in southern China, Taiwan, and Southeast Asia.

Genetic studies have revealed that in Prunus spp., both $\mathrm{CR}$ for dormancy release and leafing and blooming time in the field are quantitative polygenic traits that are genetically determined (Arora et al., 2003; Tzonev and Erez, 2003). In Prunus, the CR rather than the heat requirement is the major factor determining leafing and blooming time (Egea et al., 2003; Fan et al., 2010; Ruiz et al., 2007; Sánchez-Pérez et al., 2012). Early genetic studies in apple and apricot have indicated that the lowchill characteristic is dominant and results from the involvement of at least one dominant gene (Hauagge and Cummins, 1991; Tzonev and Erez, 2003); recent reports however, have questioned this hypothesis (Campoy et al., 2011b; Fan et al., 2010) and further evidence is required to determine whether the low-chill characteristic is dominant in Prunus.

The first successful comprehensive study on flower bud CR quantitative trait locus (QTL) analysis in Prunus was published by Fan et al. (2010) using peach. They used an $\mathrm{F}_{2}$ population of 378 genotypes, developed from two genotypes with contrasting $\mathrm{CR}$, for map construction and QTL detection. QTLs for CR were found in linkage groups of G1, G4, G5, G6, G7, and G8 in the Prunus $(\mathrm{n}=8)$ genetic map. Among these, one major
QTL (LOD > 18) in G1 was also detected as a QTL for heat requirement and blooming date, suggesting that there may be one unified temperature sensing system in this region that regulates $\mathrm{CR}$ and leads to blooming. In apricot, the use of $F_{1}$ pseudo-testcross progenies identified QTLs associated with the CR of vegetative buds, in G1, G2, G3, G5, and G8 (Olukolu et al., 2009). In almond, a major QTL for CR of flower buds was located in G4, and minor QTLs were located in G1, G3, and G7 (Sánchez-Pérez et al., 2012). Among these, QTLs for blooming time overlapped with QTLs for CR in G1 and G4. Unfortunately, none of these identified QTLs in Prunus have yet been fine-mapped and efforts are continuing (Zhebentyayeva et al., 2014). Genetic and QTL studies on the blooming time of Prunus have been conducted by several researchers (Olukolu and Kole, 2012). Although this trait is expected to be more affected by environmental factors in comparison to CR, Dirlewanger et al. (2012) reported that several QTLs for the blooming time of three Prunus species (peach, apricot, and sweet cherry) were highly stable, suggesting that they were not affected by climate change. Recently developed techniques, such as genotyping-by-sequencing (GBS) using second-generation sequencing (SGS), such as Illumina sequencing, and the release of a well-assembled whole peach genome (The International Peach Genome Initiative, 2013) and other Prunus genome sequences, such as the Japanese apricot genome (Zhuang et al., 2012), will accelerate QTL studies of CR in Prunus (Bielenberg, 2013). Currently, QTL studies of Japanese apricot $\mathrm{CR}$, blooming and leafing time are ongoing at the Kyoto University Experimental Farm, Takatsuki, Japan.

\section{Biochemical and molecular biological approaches for Prunus dormancy study}

Early biochemical studies on Prunus bud dormancy regulation have investigated seasonal carbohydrate concentration changes and carbohydrate absorption potentials (Marquat et al., 1999). During dormancy, the bud exhibited a low sugar absorption potential, while later during dormancy release absorption potentials increased. Soluble sugars accumulated during winter. The active sucrose absorption could be explained by increased activity of plasma membrane $\mathrm{H}^{+}$-ATPase (Aue et al., 1999; Gévaudant et al., 2001). Bonhomme et al. (2005) investigated the influence of cold deprivation during dormancy on the carbohydrate content of buds. Since sugar concentrations remained high during cold deprivation, bud necrosis caused by cold deprivation could be the consequence of an inability to use carbohydrate reserves. Another example of a biochemical study was the analysis of seasonal changes of the water status of peach flower buds by magnetic resonance imaging (Yooyongwech et al., 2008). Surprisingly, there have only been a few studies on the analysis of phytohormone contents during dormancy transition in Prunus. These include analyses by immunoassay (Ramina et al., 1995) 
and gas chromatography (Luna et al., 1990); however, conclusive results have yet to be obtained. Several studies have investigated the effects of the external application of phytohormones such as GA (Reinoso et al., 2002) and cytokinin (Campoy et al., 2010) on bud burst in Prunus. As the crucial roles of ABA and GA in seed dormancy regulation become more evident (Finkelstein et al., 2008), it is becoming more important that the association of hormonal content with dormancy regulation is taken into account.

One of the early proteomic approaches was to analyze bud or bark protein changes associated with the seasonal changes of dormancy in peach (Arora et al., 1992). Dehydrins, such as late embryogenesis abundant (LEA) proteins were identified as being associated with dormancy transition (Arora et al., 1994, 1996). Yamane et al. (2006) found that seasonal patterns of a dehydrin protein and transcript accumulation differed between two Japanese apricot cultivars, with greater accumulation over a longer period in late flowering 'Nanko' than in early flowering 'Ellching'. This supports the findings reported by Artrip et al. (1997) for peach dehydrin accumulation between evergreen and deciduous genotypes. Dehydrins are believed to protect plant cells against cellular dehydration and are therefore expected to accumulate in cold-hardened tissues. Therefore, dehydrins are thought to be more closely associated with cold and/or drought hardiness than with dormancy regulation (Rowland and Arora, 1997). However, Faust et al. (1997) proposed that dehydrins bind water, leading to freeze protection and a simultaneous deepening of dormancy. Yakovlev et al. (2008) also speculated that dehydrin expression was related to the timing of bud burst in Norway spruce (Betula pubescens Ehrh.). Recently, proteomics studies in Japanese apricot using matrix-assisted laser desorption/ionization time of flight/time of flight mass spectrometry (MALDI-TOF/TOF MS) identified 34 differentially expressed proteins during dormancy phase transition among more than 400 highly reproducible proteins (Zhuang et al., 2013b). In the future, developments in techniques such as metabolomics and hormonomics will provide us with a more comprehensive picture of the biochemical aspects of the regulation of bud dormancy release and of bud break in Prunus.

During the last decade, marked progress in the understanding of the molecular aspects of bud dormancy regulation has been made through transcriptomic approaches. The history of Prunus transcriptomic tool development is summarized by Trainotti et al. (2012). Initial attempts to discover genes related to bud dormancy release used strategies of relatively small-scale expression profiling at the genomic level. These included the cDNA-AFLP technique in apricot (Čechová et al., 2012) and the RNA subtraction technique in Japanese apricot (Yamane et al., 2008) and peach (Leida et al., 2010, 2012). Then, strategies moved to a more comprehensive genome-wide basis that used RNA sequencing with SGS (RNA-seq)
(Habu et al., 2012; Zhong et al., 2013) or microarray analysis (Habu et al., 2014) in Japanese apricot. These new techniques were also applied to bud dormancy studies of temperate fruit trees other than Prunus, such as Japanese pear (Bai et al., 2013; Liu et al., 2012; Nishitani et al., 2012) and grapevine (Díaz-Riquelme et al., 2012). Recent findings using gene ontology analysis suggested that some characteristic gene networks, including the rhythmic process, reproductive process, stress response, and metabolic process, were possibly involved in dormancy release of these temperate fruit trees and ornamental trees (Gai et al., 2013) (Table 1). Currently, third-generation sequencing technology is being developed. This will allow direct sequencing of RNA molecules and therefore omit the cDNA preparation and amplification steps that are presently required for the SGS system, and which may bring bias into the results. In the future, this newly developed sequencing technique is expected to facilitate a better understanding of the molecular aspects of the regulation of bud dormancy release in Prunus.

\section{1) Identification of DORMANCY-ASSOCIATED MADS- box genes in Prunus}

As described above, functional genomics could promote the discovery of gene function and identify gene networks associated with bud dormancy regulation at the transcript level on a genome-wide basis. In addition, the use of functional genomics can be useful in breeding as functional genomics approaches can be used to generate robust molecular markers for bud dormancy traits. The next step will require the functional validation of candidate genes and gene networks and validation of the marker (allele)-trait relationship between the genotype and phenotype. In model plants, functional validation is often achieved by ectopic expression and gene silencing. Much effort has been made for the development of a transformation system for Prunus (Gao et al., 2010); however, the efficiency of transformation remains low. Nonetheless, transformation studies using a heterologous plant genetic system can occasionally be used as an alternative approach. The discussion now focuses on one such candidate gene that regulates bud dormancy release and bud break of Japanese apricot and peach, from its discovery to functional characterization by transgenic studies.

Yamane et al. (2008) performed RNA subtraction to identify genes expressed preferentially in deep-dormant buds, which are March buds from trees grown under cold deprivation from Oct. to March, compared to lessdormant buds, which are March buds from cold-exposed field-grown trees of Japanese apricot. The aim was to identify candidates for internal factors that maintain a bud dormant state and prevent it from dormancy release. This work identified a MADS-box gene with dormancy-associated expression. Seasonal expression analysis suggested that the gene was up-regulated during bud 


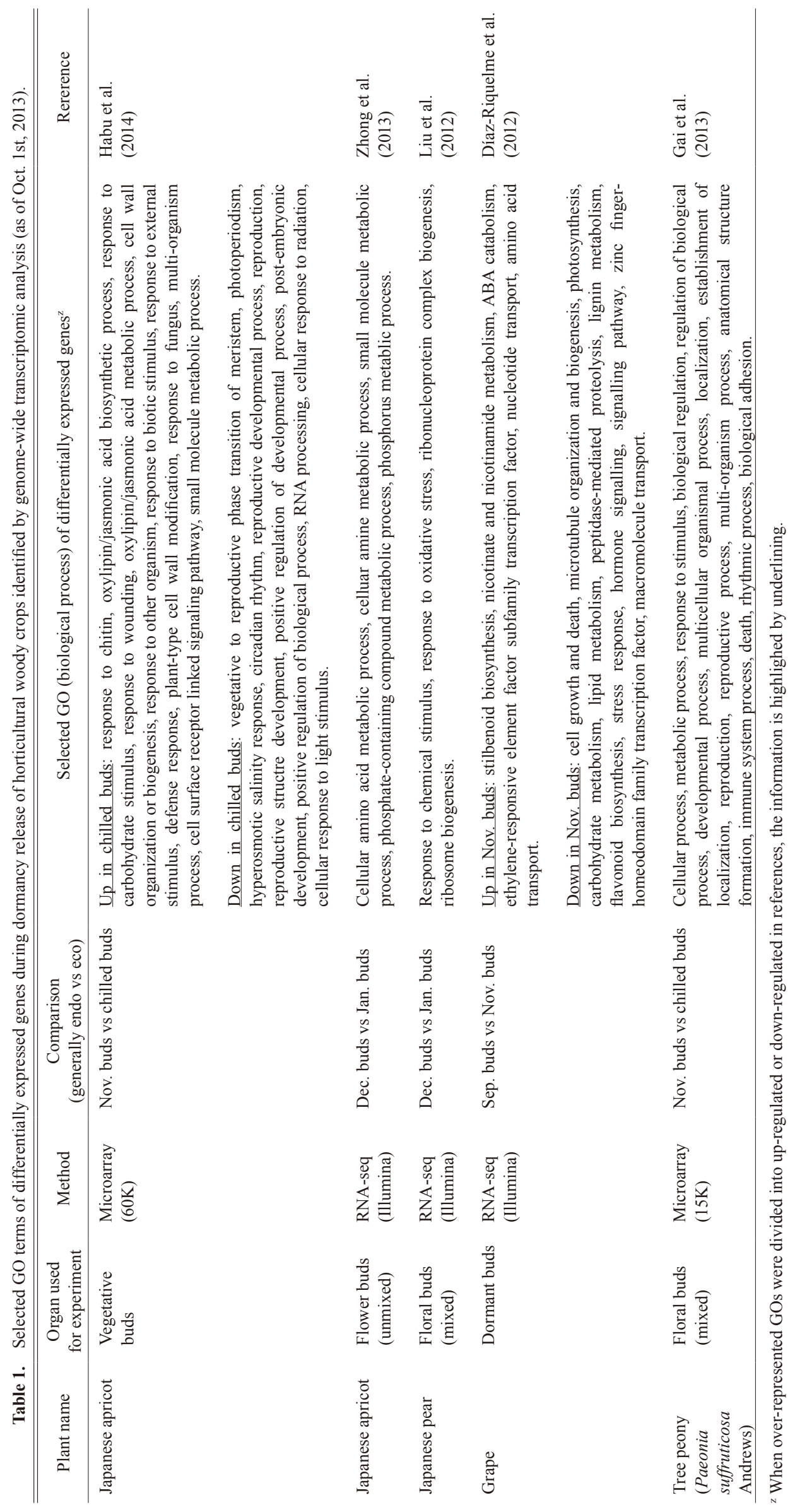


dormancy progression, and down-regulated during dormancy release. Full-length cDNA cloning of the MADSbox gene and phylogenetic analysis revealed that the gene was similar to the StMADS11 clade MADS-box genes of Arabidopsis, such as SHORT VEGETATIVE PHASE (SVP) and AGAMOUS-LIKE24 (AGL24) (Yamane et al., 2008). Bielenberg et al. (2008) independently identified six StMADS11 clade MADS-box genes as candidate genes associated with terminal bud formation in peach. Early studies had identified a mutant that failed to cease growth and to enter dormancy under dormancy-inducing conditions in peach; this is known as evergrowing (evg) (USDA PI442380) and was first identified in southern Mexico (Rodriguez et al., 1994). The evg trait segregates as a single recessive nuclear gene (Rodriguez et al., 1994). Wang et al. (2002) generated an $F_{2}$ mapping population for the segregating evg trait and found that evg was located in G1. Sequencing and expression analysis of the evg locus identified six StMADS11 (SVP/AGL24)clade MADS-box genes as candidate genes associated with terminal bud formation in peach (Bielenberg et al., 2008). These were named DORMANCY-ASSOCIATED MADS-box 1-6 (DAM1-6) genes. The gene Yamane et al. (2008) found in Japanese apricot appears to be an ortholog of peach DAM6 and was named PmDAM6.

\section{2) Expression analysis of DAM genes}

In the Japanese apricot genome, six tandem arrayed PmDAM genes (PmDAM1-PmDAM6) have been identified (Sasaki et al., 2011; Zhang et al., 2012). Seasonal expression analysis using reverse transcriptionquantitative PCR (RT-qPCR) analysis of PmDAM genes (Sasaki et al., 2011), genome-wide transcriptomic analyses using the Japanese apricot EST dormant bud database (http://bioinf.mind.meiji.ac.jp/JADB/) (Habu et al., 2012) and 60K-microarray analysis (Habu et al., 2014) demonstrated that PmDAM genes were preferentially expressed in dormant buds and down-regulated during the dormancy release of lateral vegetative buds (Fig. 4). Moreover, both RT-qPCR and microarray analysis revealed that all six PmDAM genes were down-regulated following artificial prolonged cold exposure (Fig. 5). Among them, the expression levels of PmDAM1 to PmDAM3 decreased long before dormancy release, and at a similar rate in both high-chill ('Nanko') and low-chill ('Ellching') genotypes. Interestingly, in the high-chill genotype, a short period of cold exposure led to a slight increase in PmDAM4 to PmDAM6 expression, whereas in the low-chill genotype, the same treatment repressed PmDAM4 to PmDAM6 expression. The results may indicate that the low-chill genotype reacts to cold temperature in Oct. as chilling but the high-chill genotype does not. Alternatively, a certain amount of chilling accumulation may be necessary for PmDAM4 to PmDAM6 downregulation in the high-chill genotype. The distinct changes in PmDAM4 to PmDAM6 expression may possibly contribute to the different amounts of chilling requirements for dormancy release of the genotypes. This suggests that there is an association of PmDAMs with the genetic control of chilling requirement for dormancy release. Zhong et al. (2013) recently conducted RNA-seq using Japanese apricot flower buds of an early-flowering genotype and demonstrated that PmDAM3, PmDAM5, and PmDAM6 were abundantly expressed in endodormant (November and December) to ecodormant (January) buds; their expression was negatively correlated with bud-burst frequency (Zhong et al., 2013). In peach, six $D A M$ genes showed distinct seasonal expression changes in the shoot apex. Peach DAM1,DAM2, and DAM4 were most closely associated with terminal bud formation ( $\mathrm{Li}$ et al., 2009), whereas peach DAM5 and DAM6 expression was negatively correlated with the time required for terminal bud break in peach (Jimenéz et al., 2010). Negative correlation of peach PpDAM5 and PpDAM6 expression with the time required for bud break was also reported for lateral vegetative (Yamane et al., 2011a) and flower (Yamane et al., 2011b, c) buds. In other temperate fruit trees, down-regulation of the $S V P$-like gene during dormancy release has been reported in raspberry (Rubus idaeus L.) (Mazzitelli et al., 2007). In Japanese pear, the expression of the DAM-like gene MADS13 was upregulated towards dormancy establishment and downregulated towards dormancy release (Saito et al., 2013). Wu et al. (2012) suggested that $S V P$-like genes in kiwifruit (Actinidia spp.) may have distinct roles in dormancy and flowering. In the perennial herbaceous species leafy spurge (Euphorbia esula), the DAM homologs DAMI and $D A M 2$ are associated with dormancy induction (Horvath et al., 2010).

\section{3) Functional characterization of DAM genes}

To elucidate the biological functions of PmDAM6, hybrid poplar ( $P$. tremula $\times$ P. tremuloides; clone T89) plants constitutively expressing PmDAM6 under the control of the cauliflower mosaic virus $35 \mathrm{~S}$ promoter (35S:PmDAM6) were generated, and phenotypes were compared with control plants that were either wildtype poplar or poplar transformed with an empty vector (Sasaki et al., 2011). When grown under long day (LD) conditions (16h light $/ 8 \mathrm{~h}$ dark), the shoot growth of 35S:PmDAM6 poplars was inhibited (Fig. 6A). In addition, 35S:PmDAM6 poplars set terminal buds earlier than control poplars (Fig. 6B). Shoot growth was inhibited and terminal bud set was observed earlier in 35S:PmDAM6 poplars relative to controls, even under greenhouse conditions (air cooling was set at $25^{\circ} \mathrm{C}$, therefore kept under $25^{\circ} \mathrm{C}$ ) with natural daylength in Kyoto, from April to Aug. 2012 and 2013 (Fig. 6C, D). However, the growth of suckers was stimulated more in 35S:PmDAM6 plants than in controls. After terminal bud set was observed even in control plants in the same greenhouse from April to Aug. 2012, two different experiments were conducted. In experiment 1 , trees were defoliated and transferred to a greenhouse (approximately $25^{\circ} \mathrm{C}$, natural daylength). 


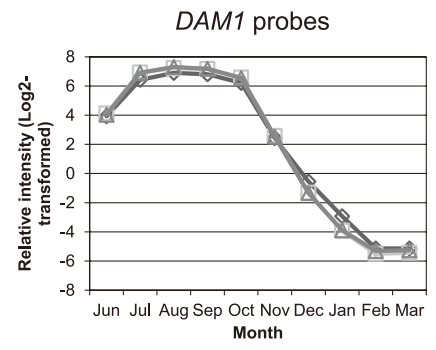

DAM4 probes

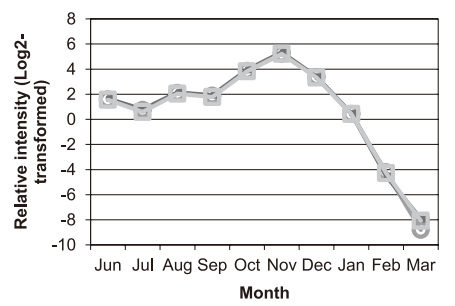

B. RT-qPCR

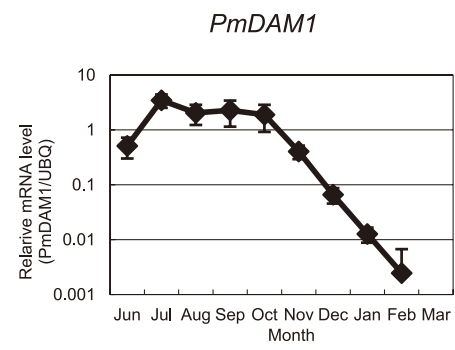

PmDAM4

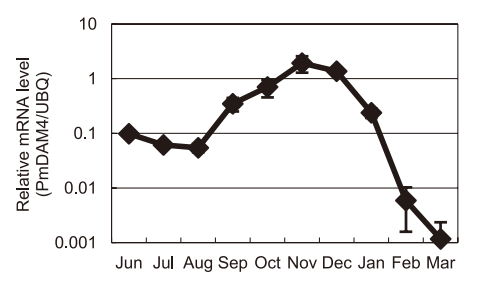

Month

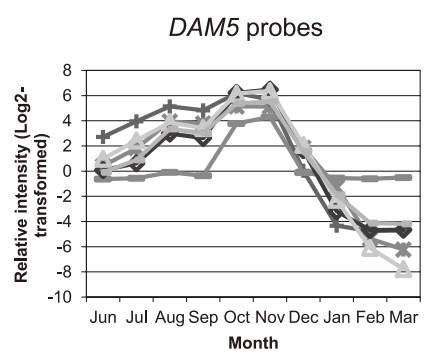

PIDAM2

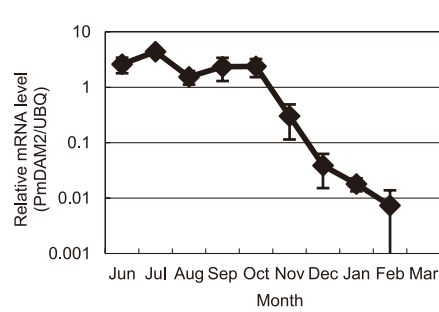

PmDAM5

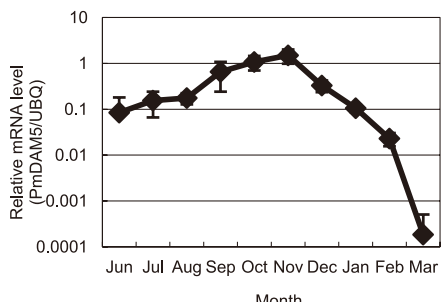

DAM3 probe

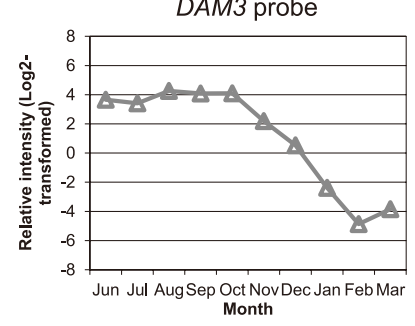

DAM6 probes

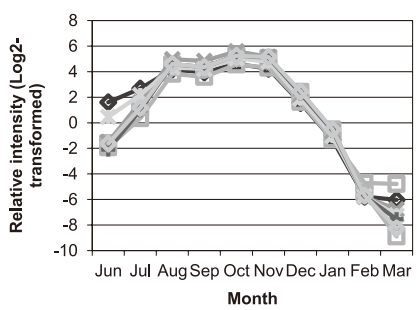

Month

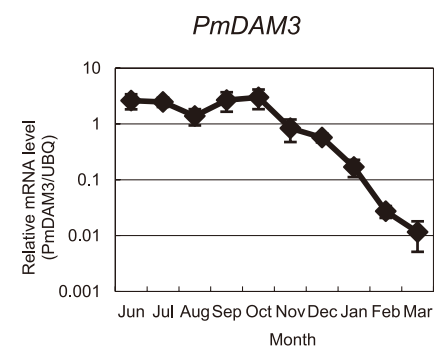

PmDAM6

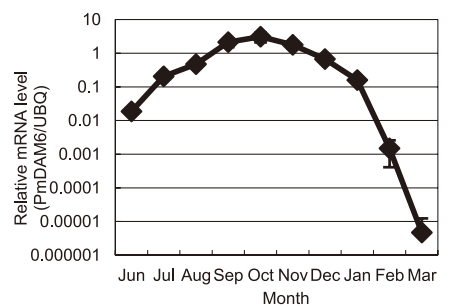

Fig. 4. Seasonal expression changes of PmDAM1-PmDAM6 genes in Japanese apricot 'Nanko'. (A) Microarray results (Habu et al., 2014) (B) RT-qPCR results (Sasaki et al., 2011). In A, three $D A M 1$, one $D A M 3$, three $D A M 4$, six DAM5, and seven DAM6-annotated probes are shown in each graph. No $D A M 2$-annotated probe was loaded on the $60 \mathrm{~K}$ microarray.

Lateral bud opening was observed after one to two months in some of the 35S:PmDAM6 and control poplars; however, some 35S:PmDAM6 poplars showed earlier lateral bud opening than the control. In experiment 2 , trees were defoliated and terminal portions of shoots were removed from each plant (decapitated), then trees were transferred to a greenhouse (approximately $25^{\circ} \mathrm{C}$, natural daylength). Bud burst was observed in the buds at the terminal position in the control trees, whereas first bud burst was observed in buds at the base position or from suckers, and the time to bud burst was later in some 35S:PmDAM6 trees compared to the control. Finally, buds in the upper position opened in some 35S:PmDAM6 plants. Collectively, these results suggested that overexpression of PmDAM6 in poplar inhibited apical growth during the active growing season but could not maintain all parts of the trees in deep dormancy.

Phenotypic observation of 35S:PmDAM6 poplar trees is ongoing, and dormancy release and bud break under chilling exposure and subsequent forcing conditions are still being assessed. The biological function of Japanese apricot $D A M \mathrm{~s}$ during dormancy will be further clarified following these experiments. Hopefully, transgenic studies using Japanese apricot will be performed despite the 

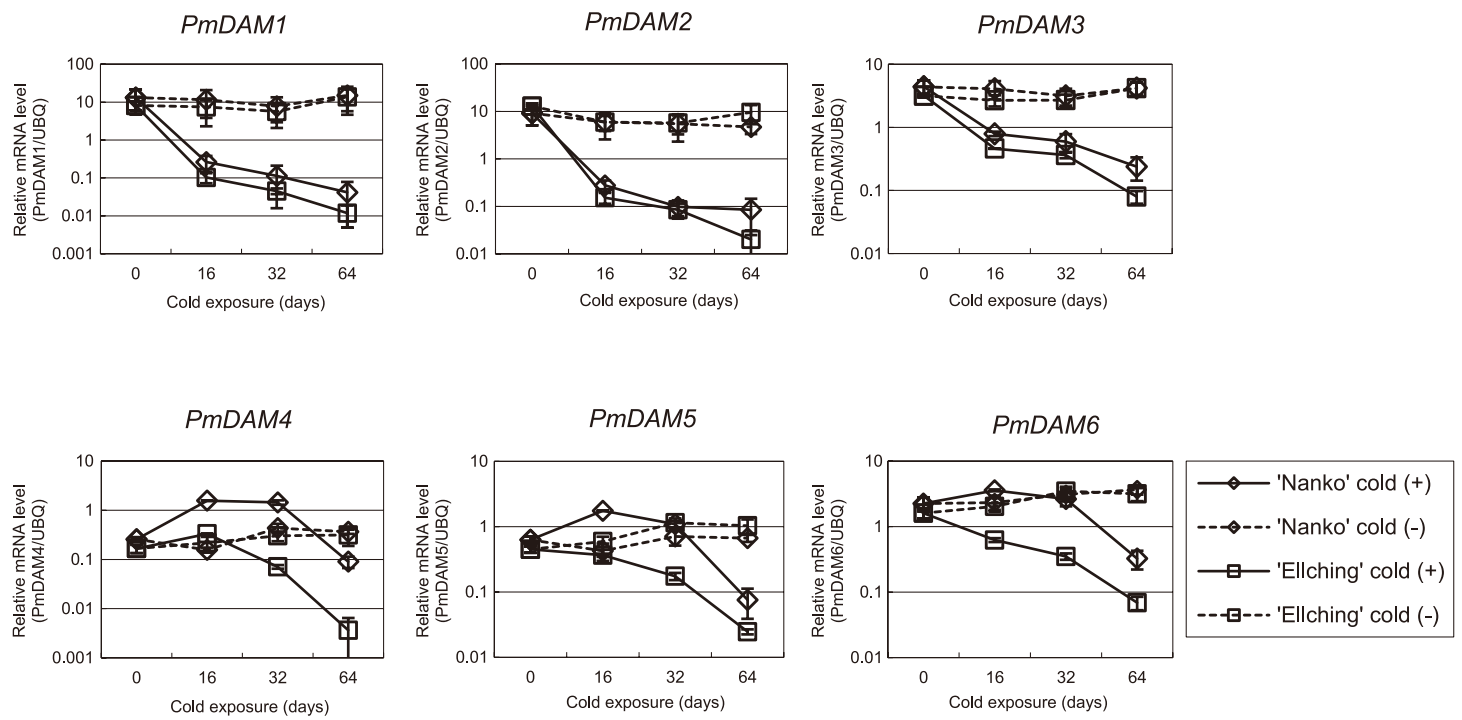

Fig. 5. Expression changes of PmDAM1-PmDAM6 by prolonged cold exposure (Sasaki et al., 2011). Branches collected in October were placed in cold $(+)$ or cold $(-)$ chambers for $0,16,32$, or 64 days. 'Nanko' had a higher chilling requirement for bud break than 'Ellching'. Bud burst was not observed in 'Nanko' after 0,16 , and 32 days of cold and was finally observed after 64 days of cold. On the other hand, bud burst of 'Ellching' was observed when 32 days of cold treatment was applied.

A.

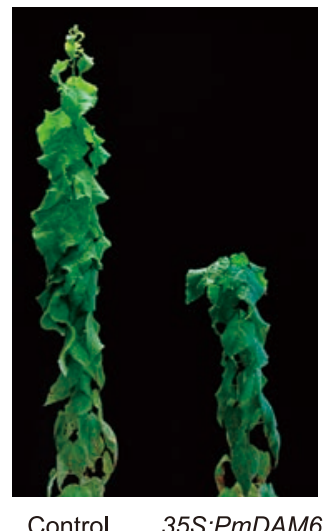

D.
B.

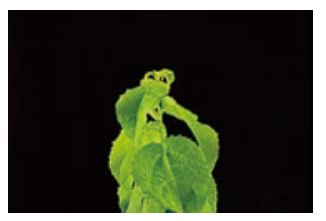

Control

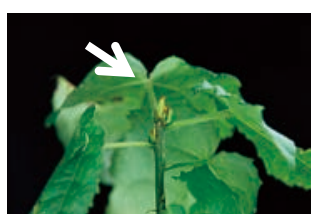

35S:PmDAM6
C.

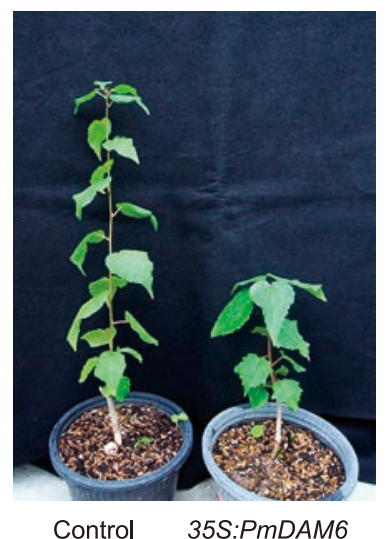

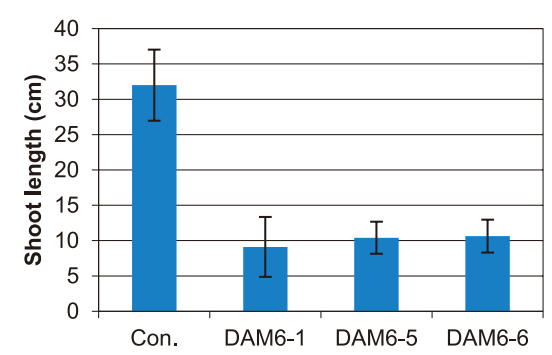

Fig. 6. Phenotypic observations of transgenic poplar plants overexpressing PmDAM6. (A) Shoot growth of 35S:PmDAM6 poplar was inhibited when grown under LD conditions (Sasaki et al., 2011). (B) Terminal bud set (indicated by arrow) was observed earlier in 35S:PmDAM6. (C) Shoot growth of 35S:PmDAM6 was also inhibited when grown in isolated greenhouse conditions under natural daylengths. (D) Averaged shoot lengths of three lines of 35S:PmDAM6 poplars (DAM6-1, DAM6-5, and DAM6-6) and one control poplar with SD are shown ( $\mathrm{n}=4-5)$.

lack of acceptable transformation efficiency (Yamane et al., 2013). The current working hypothesis of the biological role of PmDAM6 in Japanese apricot is that it participates in the inhibition of tip growth of lateral veg- etative buds during dormancy, but does not appear to be the single determinant of bud dormancy regulation. Because the expression of all Japanese apricot DAMs decreased when most buds were ready to burst in the 
field (Habu et al., 2012, 2014; Sasaki et al., 2011; Zhong et al., 2013) in response to chilling exposure (Habu et al., 2014; Sasaki et al., 2011), DAMs are expected to take part in chilling-mediated dormancy release and resumption of growth. Additionally, it has been reported that in a peach genotype a major QTL for CR and bloom date overlapped the genomic regions where peach DAMs are located (Fan et al., 2010; Zhebentyayeva et al., 2014). However, questions remain as to whether DAMs play a central role in bud dormancy regulation of Japanese apricot and peach. Firstly, DAMs expression levels were not affected when low-chill peach dormancy was broken by dormancy breaking reagent, cyanamide, in October (Hosaka et al., 2012), although cyanamide could decrease $D A M$ expression when high-chill peach dormancy was broken by cyanamide in December (Yamane et al., 2011a). Secondly, in the early flowering Japanese apricot cultivar 'Taoxingmei', digital expression of DAMs in flower buds was maintained at high levels in ecodormancy (Jan.) in comparison to that observed in endodormancy (Dec.), and decreased during February (Zhong et al., 2013). This is not consistent with the dormancyassociated expression patterns of $P m D A M \mathrm{~s}$ in vegetative buds (Sasaki et al., 2011) and peach DAMs in flower buds (Jimenéz et al., 2010; Yamane et al., 2011b, c). Recently, chromatin modifications in the peach DAM6 gene were investigated to characterize the repression mechanism of DAM6 expression during dormancy release (Leida et al., 2012). Further functional studies, including the identification and analyses of the target genes of DAM transcription factors, will be required to determine the molecular and biological function of $D A M \mathrm{~s}$.

\section{Conclusion and future studies}

Winter dormancy of woody perennials is a complex trait involving many genetic networks that are regulated under the influence of environmental factors. Although PmDAMs were identified as candidates for bud dormancy regulation in Japanese apricot, many other genes, proteins, and metabolites are likely to be involved in this trait. For example, the association of a SOC1-like MADS-box gene with chilling requirements was recently found in apricot (Trainin et al., 2013), and European plum ( $P$. domestica) trees overexpressing poplar $F T 1$ have a reduced chilling requirement for bud break (Srinivasan et al., 2012). There is accumulating evidence of the possible involvement of MADS-box genes and other flowering-related genes in dormancy regulation (Horvath, 2009). Furthermore, recent genome-wide transcriptomic studies have suggested significant roles for phytohormones in the dormancy phase transition of various plant species (Bai et al., 2013; Díaz-Riquelme et al., 2012; Gai et al., 2013; Habu et al., 2014; Liu et al., 2012; Zhong et al., 2013; Zhuang et al., 2013a). Although this review focused on bud dormancy regulation, dormancy is not only a trait of bud phenology but one of the seasonal growth-regulatory phases for entire trees; thus our final goal should be to uncover how entire trees are induced and maintained in the dormancy state and subsequently released from dormancy following chilling exposure.

For $D A M$ genes, the roles of $D A M$ homologs in fruit tree species other than Prunus should also be clarified since DAM (SVP) homologs seem to be related to the dormancy release of not only peach and Japanese apricot but also Japanese pear (Saito et al., 2013), raspberry (Matzzitelli et al., 2007), and kiwifruit (Wu et al., 2012). However, their role has been reported to be less or not significantly related to that of grape (Díaz-Riquelme et al., 2012) and leafy spurge (Horvath et al., 2010). Elucidation of the molecular basis of dormancy regulation in temperate fruit tree species could enable artificial control of dormancy through innovated cultural and chemical practices. It will also lead to the development of rapid breeding techniques such as marker-assisted seedling selection. The author's group is seeking to advance research in this area with the aim of creating innovations that will elevate sustainable fruit production worldwide.

\section{Acknowledgements}

Most of the studies of Japanese apricot vegetative bud dormancy described in this review were performed by Dr. Tsuyoshi Habu (Ehime University), Dr. Ryuta Sasaki (Center for Ecological Research, Kyoto University), and numerous graduate students in the Laboratory of Pomology, Graduate School of Agriculture, Kyoto University, along with the author. The author deeply appreciates their assistance. The author would also like to thank Dr. Ryuta Sasaki and Dr. Ryutaro Tao (Kyoto University) for providing valuable comments on this review.

\section{Literature Cited}

Arora, R. and M. E. Wisniewski. 1994. Cold acclimation in genetically related (sibling) deciduous and evergreen peach, Prunus persica. II. A 60-kilodalton bark protein in cold acclimated tissues of peach is heat-stable and related to the dehydrin family of proteins. Plant Physiol. 105: 95-101.

Arora, R., L. J. Rowland and K. Tanino. 2003. Induction and release of bud dormancy in woody perennials: A science comes of age. HortScience 38: 911-921.

Arora, R., M. E. Wisniewski and L. J. Rowland. 1996. Cold acclimation and alterations in dehydrin-like and bark storage proteins in the leaves of sibling deciduous and evergreen peach. J. Amer. Soc. Hort. Sci. 121: 915-919.

Arora, R., M. E. Wisniewski and R. Scorza. 1992. Cold acclimation in genetically related (sibling) deciduous and evergreen peach, Prunus persica. I. Seasonal changes in cold hardiness and polypeptides of bark and xylem tissues. Plant Physiol. 99: 1562-1568.

Artrip, T. S., A. M. Callahan, C. L. Bassett and M. E. Wisniewski. 1997. Seasonal expression of dehydrin gene in sibling deciduous and evergreen peach, Prunus persica. Plant Mol. Biol. 33: 61-70.

Atkinson, C. J., R. M. Brennan and H. G. Jones. 2013. Declining chilling and its impact on temperate perennial crops. Env. Exp. Bot. 91: 48-62. 
Aue, H-L., I. Lecomte, M. Gendraud and G. Pétel. 1999. Change in plasma membrane ATPase activity during dormancy release of vegetative peach-tree buds. Physiol. Plant. 106: 41-46.

Bai, S., T. Saito, D. Sakamoto, H. Fujii and T. Moriguchi. 2013. Transcriptome analysis of Japanese pear (Pyrus pyrifolia Nakai) flower buds transitioning through endodormancy. Plant Cell Physiol. 54: 1132-1151.

Bielenberg, D. G. 2013. Use of Genotyping-By-Sequencing for QTL mapping of chilling requirement and bloom date in peach. Abstr. Plant and Animal Genome XXI Conference.

Bielenberg, D. G., Z. Li, T. Zhebentyayeva, S. Fan, G. L. Reighard, R. Scorza, and A. G. Abbott. 2008. Sequencing and annotation of the evergrowing locus in peach [Prunus persica (L.) Batsch] reveals a cluster of six MADS-box transcription factors as candidate genes for regulation of terminal bud formation. Tree Genet. Gen. 4: 495-507.

Böhlenius, H., T. Huang, L. Charbonnel-Campaa, A. M. Brunner, S. Jansson, S. H. Strauss and O. Nilsson. 2006. CO/FT regulatory module controls timing of flowering and seasonal growth cessation in trees. Science 312: 1040-1043.

Bonhomme, M., R. Rageau, A. Lacointe and M. Gendraud. 2005. Influences of cold deprivation during dormancy on carbohydrate contents of vegetative and floral primordial and nearby structures of peach buds (Prunus persica L. Batch). Sci. Hortic. 105: 223-240.

Bräutigam, K., K. J. Vining, C. Lafon-Placette, C. G. Fossdal, M. Mirouze, J. G. Marcos, S. Fluch, M. F. Fraga, M. Á. Guevara, D. Abarca, Ø. Johnsen, S. Maury, S. H. Strauss, M. M. Campbell, A. Rohde, C. Díaz-Sala and M-T. Cervera. 2013. Epigenetic regulation of adaptive responses of forest tree species to the environment. Ecol. Evol. 3: 399-415.

Campoy, J. A., D. Ruiz and J. Egea. 2010. Effects of shading and thidiazuron + oil treatment on dormancy breaking, blooming and fruit set in apricot in a warm-winter climate. Sci. Hortic. 125: 203-210.

Campoy J. A., D. Ruiz and J. Egea. 2011a. Dormancy in temperate fruit trees in a global warming context: A review. Sci. Hortic. 130: 357-372.

Campoy, J. A., D. Ruiz, J. Egea, D. J. G. Rees, J. M. Celton, P. Martínez-Gómez. 2011b. Inheritance of flowering time in apricot (Prunus armeniaca L.) and analysis of linked quantitative trait loci (QTLs) using simple sequence repeat (SSR) markers. Plant Mol. Biol. Rep. 29: 404-410.

Čechová, J., M. Baránek, B. Krška and M. Pidra. 2012. Screening of differentially expressed genes during the end of endogenous dormancy of flower buds in Prunus armeniaca L. Plant Growth Regul. 67: 141-150.

Cooke, J. K., M. E. Eriksson and O. Junttila. 2012. The dynamic nature of bud dormancy in trees: environmental control and molecular mechanisms. Plant Cell Environ. 35: 1707-1728.

Crabbé, J. 1994. Dormancy, p. 597-611. In: C. J. Arntzen and E. M. Ritter (eds.). Encyclopedia of agricultural science. Vol. 1. Academic Press, INC., New York.

Díaz-Riquelme, J., J. Grimplet, J. M. Martínez-Zapater and M. J. Carmona. 2012. Transcriptome variation along bud development in grapevine (Vitis vinifera L.). BMC Plant Biol. 12: 181. DOI: 10.1186/1471-2229-12-181. <http://www. biomedcentral.com/bmcplantbiol/>.

Dirlewanger, E., J. Quero-García, L. L. Dantec, P. Lambert, D. Ruiz, L. Dondini, E. Illa, B. Quilot-Turion, J-M. Audergon, S. Tartarini, P. Letourmy and P. Arús. 2012. Comparison of the genetic determinism of two key phonological traits, flowering and maturity dates, in three Prunus species: peach, apricot and sweet cherry. Heredity 109: 280-292.

Egea, J., E. Ortega, P. Martinez-Gómez and F. Dicenta. 2003.
Chilling and heat requirements of almond cultivars for flowering. Env. Exp. Bot. 50: 79-85.

Erez, A. 2000. Bud dormancy; phenomenon, problems and solutions in the tropics and subtropics. p. 17-48. In: A. Erez (ed.). Temperate fruit crops in warm climates. Kluwer Academic Publishers, Dordrecht.

Erez, A., M. Faust and M. J. Line. 1998. Changes in water status in peach buds on induction, development and release from dormancy. Sci. Hortic. 73: 111-123.

Erez, A., R. M. Samish and S. Lavee. 1966. The role of light in leaf and flower bud break of the peach (Prunus persica). Physiol. Plant. 19: 650-659.

Fan, S., D. G. Bielenberg, T. N. Zhebentyayeva, G. L. Reighard, W. R. Okie, D. Holland and A. G. Abbott. 2010. Mapping quantitative trait loci associated with chilling requirement, heat requirement and bloom date in peach (Prunus persica). New Phytol. 185: 917-930.

Faust, M., A. Erez, L. J. Rowland, S. Y. Wang and H. A. Norman. 1997. Bud dormancy in perennial fruit trees: physiological basis for dormancy induction, maintenance, and release. HortScience 32: 623-629.

Finkelstein, R., W. Reeves, T. Ariizumi and C. Steber. 2008. Molecular aspects of seed dormancy. Annu. Rev. Plant Biol. 59: $387-415$.

Fishman, S., A. Erez and G. A. Couvillon. 1987a. The temperature dependence of dormancy breaking in plants: mathematical analysis of a two-step model involving a cooperative transition. J. Theor. Biol. 124: 473-483.

Fishman, S., A. Erez and G. A. Couvillon. 1987b. The temperature dependence of dormancy breaking in plants: computer simulation of processes studied under controlled temperature. J. Theor. Biol. 126: 309-321.

Gai, S., Y. Zhang, C. Liu, Y. Zhang and G. Zheng. 2013. Transcript profiling of Paoenia ostii during artificial chilling induced dormancy release identifies activation of GA pathway and carbohydrate metabolism. PLoS ONE 8: e55297. DOI: 10.1371/journal.pone.0055297. <http://www.plosone.org/>.

Gao, M., M. Kawabe, T. Tsukamoto, H. Hanada, and R. Tao. 2010. Somatic embryogenesis and Agrobacterium-mediated transformation of Japanese apricot (Prunus mume) using immature cotyledons. Sci. Hortic. 124: 360-367.

Gao, Z., W. Zhuang, L. Wang, J. Shao, X. Luo, B. Cai and Z. Zhang. 2012. Evaluation of chilling and heat requirements in Japanese apricot with three models. HortScience 47: 18261831.

Gariglio, N., D. E. G. Rossia, M. Mendow, C. Reig and M. Agusti. 2006. Effect of artificial chilling on the depth of endodormancy and vegetative and flower budbreak of peach and nectarine cultivars using excised shoots. Sci. Hortic. 108: 371-377.

Gévaudant, F., G. Pétel and A. Guilliot. 2001. Differential expression of four members of the $\mathrm{H}^{+}$-ATPase gene family during dormancy of vegetative buds of peach trees. Planta 212: 619-626.

Habu, T., H. Yamane, K. Igarashi, K. Hamada, K. Yano and R. Tao. 2012. 454-pyrosequencing of the transcriptome in leaf and flower buds of Japanese apricot (Prunus mume Sieb. et Zucc.) at different dormant stages. J. Japan. Soc. Hort. Sci. 81: 239-250.

Habu, T., H. Yamane, R. Sasaki, K. Yano, H. Fujii, T. Shimizu, T. Yamamoto and R. Tao. 2014. Custom microarray analysis for transcript profiling of dormant vegetative buds of Japanese apricot during prolonged chilling exposure. J. Japan. Soc. Hort. Sci. 83: 1-16.

Harrington, C. A., P. J. Gould and J. B. St. Clair. 2010. Modeling 
the effects of winter environment on dormancy release of Douglas-fir. Forest Ecol. Management 259: 798-808.

Hauagge, R. and J. N. Cummins. 1991. Genetics of length of dormancy period in Malus vegetative buds. J. Amer. Soc. Hort. Sci. 116: 121-126.

Hedley, P., J. R. Russell, L. Jorgensen, S. Gordon, J. A. Morris, C. A. Hackett, L. Cardle and R. Brennan. 2010. Candidate genes associated with bud dormancy release in blackcurrant (Ribes nigrum L.). BMC Plant Biol. 10: 202. DOI: 10.1186/1471-2229-10-202. <http://www.biomedcentral. $\mathrm{com} / \mathrm{bmcplantbiol} />$.

Heide, O. M. 2008. Interaction of photoperiod and temperature in the control of growth and dormancy of Prunus species. Sci. Hortic. 115: 309-314.

Heide, O. M. and A. K. Prestrud. 2005. Low temperature, but not photoperiod, control growth cessation and dormancy induction and release in apple and pear. Tree Physiol. 25: 109-114.

Horvath, D. 2009. Common mechanisms regulate flowering and dormancy. Plant Sci. 177: 523-531.

Horvath, D. P., S. Sung, D. Kim, W. Chao and J. Anderson. 2010. Characterization, expression and function of DORMANCY ASSOCIATED MADS-BOX genes from leafy spurge. Plant Mol. Biol. 73: 169-179.

Hosaka, Y., T. Akagi, H. Yamane, R. Tao and K. Yonemori. 2012. Effects of cyanamide treatment on endodormancy breaking and expressions of PpDAM5, 6 in peach cultivars requiring different chilling accumulation for budbreak. Hort. Res. (Japan) 11 (Suppl. 1): 281 (In Japanese).

Hsu, C. Y., J. P. Adams, H. Kim, K. No, C. Ma, S. H. Strauss, J. Drnevich, L. Vandervelde, J. D. Ellis, B. M. Rice, N. Wickett, L. E. gunter, G. A. Tuskan, A. M. Brunner, G. P. Page, A. Barakat, J. E. Carlson, C. W. dePamphilis, D. S. Luthe and C. Yuceer. 2011. FLOWERING LOCUS T duplication coordinates reproductive and vegetative growth in perennial poplar. Proc. Natl. Acad. Sci. USA 108: 10756-10761.

Ibáñez, C., I. Kozarewa, M. Johansson, E. Ögren, A. Rohde and M. E. Eriksson. 2010. Circadian clock components regulate entry and affect exit of seasonal dormancy as well as winter hardiness in Populus trees. Plant Physiol. 153: 1824-1833.

Jimenéz, S., G. L. Reighard and D. G. Bielenberg. 2010. Gene expression of DAM5 and DAM6 is suppressed by chilling temperatures and inversely correlated with bud break rate. Plant Mol. Biol. 73: 157-167.

Kataoka, I., A. Nishikawa, N. Kozai and K. Beppu. 2002. Pattern of dormancy and flower initiation of peach under regulated environmental conditions. J. Japan. Hort. Sci. 71 (Suppl. 2): 109 (In Japanese).

Kozarewa, I., C. Ibáñez, M. Johansson, E. Ögren, D. Mozley, E. Nylander, M. Chono, T. Moritz and M. E. Eriksson. 2010. Alteration of PHYA expression change circadian rhythms and timing of bud set in Populus. Plant Mol. Biol. 73: 143-156.

Lang, G. A. 1987. Dormancy: a new universal terminology. HortScience 22: 817-820.

Lang, G. A., J. D. Early, G. C. Martin, and R. L. Darnell. 1987. Endo-, para-, and ecodormancy: physiological terminology and classification for dormancy research. HortScience 22: 371-377.

Leida, C., A. Conesa, G. Llácer, M. L. Badenes and G. Ríos. 2012. Histone modifications and expression of DAM6 gene in peach are modulated during bud dormancy release in a cultivar-dependent manner. New Phytol. 193: 67-80.

Leida, C., J. Terol, G. Martí, M. Agustí, G. Llácer, M. L. Badenes and G. Ríos. 2010. Identification of genes associated with bud dormancy release in Prunus persica by suppression subtractive hybridization. Tree Physiol. 30: 655-666.
Li, Z., G. L. Reighard, A. G. Abbott and D. G. Bielenberg. 2009. Dormancy associated MADS genes from the EVG locus of peach [Prunus persica (L.) Batsch] have distinct seasonal and photoperiodic expression patterns. J. Exp. Bot. 60: 35213530 .

Liu, G., W. Li, P. Zheng, T. Xu, L. Chen, D. Liu, S. Hussain and Y. Teng. 2012. Transcriptomic analysis of 'Suli' pear (Pyrus pyrifolia white pear group) buds during the dormancy by RNA-Seq. BMC Genomics 13: 700. DOI: 10.1186/14712164-13-700. <http://www.biomedcentral.com/bmcgenomics/>.

Luedeling, E., E. H. Girvetz, M. A. Semenov and P. H. Brown. 2011. Climate change affects winter chill for temperate fruit and nut trees. PLoS ONE 6: e20155. DOI: 10.1371/journal. pone.0020155. <http://www.plosone.org/>.

Luna, V., M. D. Soriano, R. Bottini, C. Sheng and R. P. Pharis. 1990. Levels of endogenous gibberellins, abscisic acid, indol 3 acetic acid, and naringenin during dormancy of peach flower buds. Acta Hort. 329: 265-267.

Marquat, C., M. Vandamme, M. Gendraud and G. Pétel. 1999. Dormancy in vegetative buds of peach: relation between carbohydrate absorption potentials and carbohydrate concentration in the bud during dormancy and its release. Sci. Hortic. 79: $151-162$.

Mathiason, K., D. He, J. Grimplet, J. Venkateswari, D. W. Galbraith, E. Or and A. Fennell. 2009. Transcript profiling in Vitis riparia during chilling requirement fulfillment reveals coordination of gene expression patterns with optimized bud break. Func. Integr. Genomics 9: 81-96.

Mazzitelli, L., R. D. Hancock, S. Haupt, P. G. Walker, S. D. A. Pont, J. McNicol, L. Cardle, J. Morris, R. Viola, R. Brennan, P. E. Hedley and M. A. Taylor. 2007. Co-ordinated gene expression during phases of dormancy release in raspberry (Rubus idaeus L.) buds. J. Exp. Bot. 58: 1035-1045.

Mohamed, R., C. T. Wang, C. Ma, O. Shevchenko, S. J. dye, J. R. Puzey, E. Etherington, X. Sheng, R. Meilan, S. H. Strauss and A. M. Brunner. 2010. Populus CEN/TFL1 regulates first onset of flowering, axillary meristem identity and dormancy release in Populus. Plant J. 62: 674-688.

Nishitani, C., T. Saito, B. E. Ubi, T. Shimizu, A. Itai, T. Saito, T. Yamamoto and T. Moriguchi. 2012. Transcriptome analysis of Pyrus pyrifolia leaf buds during transition from endodormancy to ecodormancy. Sci. Hortic. 147: 49-55.

Nitsch, J. P. 1957. Growth responses of woody plants to photoperiodic stimuli. Proc. Amer. Soc. Hort. Sci. 70: 512-525.

Olsen, J. E., O. Junttila, J. Nilsen, M. E. Eriksson, I. Martinussen, O. Olsson, G. Sandberg and T. Moritz. 1997. Ectopic expression of oat phytochrome A in hybrid aspen changes critical daylength for growth and prevents cold acclimation. Plant $\mathrm{J}$. 12: $1339-1350$.

Olukolu, B. A. and C. Kole. 2012. Molecular mapping of complex traits. p. 126-157. In: C. Kole and A. G. Abbott (eds.). Genetics, genomics and breeding of stone fruits. CRC Press, Florida.

Olukolu, B. A., T. Trainin, S. Fan, C. Kole, D. Bielenberg, G. Reighard, A. Abbott and D. Holland. 2009. Genetic linkage mapping for molecular dissection of chilling requirement and budbreak in apricot (Prunus armeniaca L.). Genome 52: 819-828.

Pin, P. A. and O. Nilsson. 2012. The multifaceted roles of FLOWERING LOCUS T in plant development. Plant Cell Environ. 35: 1742-1755.

Ramina, A., M. Colauzzi, A. Masia, A. Pitacco, T, Caruso, R. Messina and G. Scalabrelli. 1995. Hormonal and climatological aspects of dormancy in peach buds. Acta Hort. 395: 
35-46.

Reinoso, H., V. Luna, C. Dauría, R. P. Pharis and R. Bottini. 2002. Dormancy in peach (Prunus persica) flower buds. VI. Effects of gibberellins and an acylcyclohexanedione (trinexapacethyl) on bud morphogenesis in field experiments with orchard trees and on cuttings. Can. J. Bot. 80: 664-674.

Richardson, E. A., S. D. Seeley and D. R. Walker. 1974. A model for estimating the completion of rest for 'Redhaven' and 'Elberta' peach trees. HortScience 1: 331-332.

Rinne, P. L., A. Welling, J. Vahala, L. Ripel, R. Ruonala, J. Kangasjärvi and C. van der Schoot. 2011. Chilling of dormant buds hyperinduces FLOWERING LOCUS T and recruits GA-inducible 1, 3- $\beta$-glucanases to reopen signal conduits and release dormancy in Populus. Plant Cell 23: 130-146.

Rinne, P. L. H., A. Welling and C. van der Schoot. 2010. Perennial life style of Populus: dormancy cycling and overwintering. p. 171-200. In: S. Jansson, R. Bhalerao and A. Groover (eds.). Genetics and Genomics of Populus. Springer, New York.

Rodriguez, J., W. B. Sherman, R. Scorza, M. Wisniewski and W. R. Okie. 1994. Evergreen peach, its inheritance and dormant behavior. J. Amer. Soc. Hort. Sci. 119: 789-792.

Rohde, A. and R. P. Bhalerao. 2007. Plant dormancy in the perennial context. Trends in Plant Sci. 12: 217-223.

Rohde, A., E. Prinsen, R. De Rycke, G. Engler, M. Van Montagu and W. Boerjan. 2002. PtABI3 impinges on the growth and differentiation of embryonic leaves during bud set in poplar. Plant Cell 14: 1885-1901.

Rohde, A., V. Storme, V. Jorge, M. Gaudet, N. Vitacolonna, F. Fabbrini, T. Ruttink, G. Zaina, N. Marron, S. Dillen, M. Steenackers, M. Sabatti, M. Morgante, W. Boerjan and C. Bastien. 2011. Bud set in poplar-genetic dissection of a complex trait in natural and hybrid populations. New Phytol. 189: 106-121.

Rowland, L. J. and R. Arora. 1997. Proteins related to endodormancy (rest) in woody perennials. Plant Sci. 126: 119-144.

Ruiz, D., J. A. Campoy and J. Egea. 2007. Chilling and heat requirements of apricot cultivars for flowering. Env. Exp. Bot. 61: 254-263.

Ruttink, T., M. Arend, K. Morreel, V. Storme, S. Rombauts, J. Fromm, R. P. Bhalerao, W. Boerjan and A. Rohde. 2007. A molecular timetable for apical bud formation and dormancy induction in poplar. Plant Cell 19: 2370-2390.

Saito, T., S. Bai, A. Ito, D. Sakamoto, T. Saito, B. E. Ubi, T. Imai and T. Moriguchi. 2013. Expression and genomic structure of the dormancy-associated MADS box genes MADS13 in Japanese pears (Pyrus pyrifolia Nakai) that differ in their chilling requirement for endodormancy release. Tree Physiol. 33: 654-667.

Samish, R. M. 1954. Dormancy in woody plants. Plant Physiol. 5: 193-204.

Sánchez-Pérez, R., F. Dicenta and P. Martínez-Gómez. 2012. Inheritance of chilling and heat requirements for flowering in almond and QTL analysis. Tree Genet. Genomes 8: 379-389.

Santamaría, M. E., R. Rodríguez, M. J. Cañal and P. E. Toorop. 2011. Transcriptome analysis of chestnut (Castanea sativa) tree buds suggests a putative role for epigenetic control of bud dormancy. Annu. Bot. 108: 485-498.

Sasaki, R., H. Yamane, T. Ooka, H. Jotatsu, Y. Kitamura, T. Akagi and R. Tao. 2011. Functional and expressional analyses of PmDAM genes associated with endodormancy in Japanese apricot (Prunus mume). Plant Physiol. 157: 485-497.

Solomon, S. 2007. Climate change 2007: the physical science basis: Working group I contribution to the fourth assessment report of the IPCC. Vol. 4. Cambridge University Press, Cambridge.
Srinivasan, C., C. Dardick, A. Callahan and R. Scorza. 2012. Plum (Prunus domestica) trees transformed with poplar FT1 results in altered architecture, dormancy requirement, and continuous flowering. PLoS ONE 7: e40715. DOI: 10.1371/journal. pone.0040715. <http://www.plosone.org/>.

Sugiura, T. and H. Honjo. 1997. A dynamic model for predicting e flowering date developed using an endodormancy break model and a flower bud development model in Japanese pear. J. Agric. Meteorol. 52: 897-900.

Sugiura, T., H. Kuroda and H. Sugiura. 2007. Influence of the current state of global warming on fruit tree growth in Japan. Hort. Res. (Japan) 6: 257-263 (In Japanese with English abstract).

Sugiura, T., D. Sakamoto, T. Asakura and H. Sugiura. 2010. The relationship between temperature and effect on endodormancy completion in the flower bud of 'Hakuho' peach. J. Agric. Meteorol. 66: 173-179.

Takamatsu, Y., T. Kitagawa, T. Tatebayashi and N. Utsunomiya. 2004. Scanning electron microscope of development of axillary buds in 'Nankoh' Japanese apricot. Hort. Res. (Japan) 3: 409-413 (In Japanese with English abstract).

Tanino, K. K., L. Kalcsits, S. Silim, E. Kendall and G. R. Gray. 2010. Temperature-driven plasticity in growth cessation and dormancy development in deciduous woody plants: a working hypothesis suggesting how molecular and cellular function is affected by temperature during dormancy induction. Plant Mol. Biol. 73: 49-65.

The International Peach Genome Initiative. 2013. The highquality draft genome of peach (Prunus persica) identifies unique patterns of genetic diversity, domestication and genome evolution. Nature Genetics 45: 487-494.

Topp, B. L., W. B. Sherman and M. C. B. Raseira. 2008. Low-chill cultivar development. p. 106-138. In: D. R. Layne and D. Bassi (eds.). The peach, botany, production and uses. CAB International, Oxfordshire.

Trainin, T., I. Bar-Ya'akov and D. Holland. 2013. ParSOC1, a MADS-box gene closely related to Arabidopsis AGL20/ $S O C 1$, is expressed in apricot leaves in a diurnal manner and is linked with chilling requirements for dormancy break. Tree Genet. Genomes 9: 753-766.

Trainotti, L., S. Cagnin, C. Forcato, C. Bonghi, A. Dhingra, T. Koepke, L. Prat, J. Maldonado and H. Silva. 2012. Functional genomics: transcriptomics. p. 292-322. In: C. Kole and A. G. Abbott (eds.). Genetics, genomics and breeding of stone fruits. CRC Press, Florida.

Tzonev, R. and A. Erez. 2003. Inheritance of chilling requirement for dormancy completion in apricot vegetative buds. Acta Hort. 622: 429-436.

Wang, Y., L. L. Georgi, G. L. Reighard, R. Scorza and A. G. Abbott. 2002. Genetic mapping of the evergrowing gene in peach [Prunus persica (L.) Batsch]. J. Hered. 93: 352-358.

Weinberger, J. H. 1950. Chilling requirements of peach varieties. Proc. Amer. Soc. Hort. Sci. 56: 122-128.

Westwood, M. N. 1993. Temperate-zone pomology: physiology and culture, third edition. Timber press, Inc. Oregon.

Wu, R. M., E. F. Walton, A. C. Richardson, M. Wood, R. P. Hellens and E. Varkonyi-Gasic. 2012. Conservation and divergence of four kiwifruit SVP-like MADS-box genes suggest distinct roles in kiwifruit bud dormancy and flowering. J. Exp. Bot. 63: 797-807.

Yakovlev, I. A., D. K. Asante, C. G. Fossdal, J. Partanen, O. Junttila and Ø. Johnsen. 2008. Dehydrins expression related to timing of bud burst in Norway spruce. Planta 228: 459-472.

Yamane, H. 2013. Seasonal and molecular control of blooming in temperate fruit trees. Bullet. Exp. Farm Kyoto Univ. (In 
Japanese with English abstract) (In press).

Yamane, H., M. Gao-Takai and R. Tao. 2013. An attempt to control expression of PmDAMs in Prunus mume by Agrobacteriummediated transformation. J. Beijing Forestry Univ. 35 (Suppl. 1): 33-37.

Yamane, H., Y. Kashiwa, E. Kakehi, K. Yonemori, H. Mori, K. Hayashi, K. Iwamoto, R. Tao and I. Kataoka. 2006. Differential expression of dehydrin in flower buds of two Japanese apricot cultivars requiring different chilling requirements for bud break. Tree Physiol. 26: 1559-1563.

Yamane, H., Y. Kashiwa, T. Ooka, R. Tao and K. Yonemori. 2008. Suppression subtractive hybridization and differential screening reveals endodormancy-associated expression of an SVP/ AGL24-type MADS-box gene in lateral vegetative buds of Japanese apricot. J. Amer. Soc. Hort. Sci. 133: 708-716.

Yamane, H., T. Ooka, H. Jotatsu, Y. Hosaka, R. Sasaki and R. Tao. 2011a. Expressional regulation of PpDAM5 and PpDAM6, peach (Prunus persica) dormancy-associated MADS-box genes, by low temperature and dormancy-breaking reagent treatment. J. Exp. Bot. 62: 3481-3488.

Yamane, H., T. Ooka, H. Jotatsu, R. Sasaki and R. Tao. $2011 \mathrm{~b}$. Expression analysis of PpDAM5 and PpDAM6 during flower bud development in peach (Prunus persica). Sci. Hortic. 129: 844-848.

Yamane, H., R. Tao, T. Ooka, H. Jotatsu, R. Sasaki and K. Yonemori. 2011c. Comparative analyses of dormancyassociated MADS-box genes, PpDAM5 and PpDAM6, in low- and high-chill peaches (Prunus persica L.). J. Japan. Soc. Hort. Sci. 80: 276-283.
Yooyongwech, S., A. K. Horigane, M. Yoshida, M. Yamaguchi, Y. Sekozawa, S. Sugaya and H. Gemma. 2008. Changes in aquaporin gene expression and magnetic resonance imaging of water status in peach tree flower buds during dormancy. Physiol. Plant. 134: 522-533.

Zhang, Q., W. Chen, L. Sun, F. Zhao, B. Huang, W. Yang, Y. Tao, J. Wang, Z. Yuan, G. Fan, Z. Xing, C. Han, H. Pan, X. Zhong, W. Shi, X. Liang, D. Du, F. Sun, Z. Xu, R. Hao, T. Lv, Y. Lv, Z. Zheng, M. Sun, L. Luo, M. Cai, Y. Gao, J. Wang, Y. Yin, $\mathrm{X}$. Xu, T. Cheng and J. Wang. 2012. The genome of Prunus mume. Nature communications 3: 1318.

Zhebentyayeva, T., S. Fan, A. Chandra, D. G. Bielenberg, G. L. Reighard, W. R. Okie and A. G. Abbott. 2014. Dissection of chilling requirement and bloom date QTLs in peach using a whole genome sequencing of sibling trees from an $\mathrm{F}_{2}$ mapping population. Tree Genet. Genomes 10: 35-51.

Zhong, W., Z. Gao, W. Zhuang, T. Shi, Z. Zhang and Z. Ni. 2013. Genome-wide expression profiles of seasonal bud dormancy at four critical stages in Japanese apricot. Plant Mol. Biol. 83: 247-264.

Zhuang, W., Z. Gao, L. Wang, W. Zhong, Z. Ni and Z. Zhang. 2013a. Comparative proteomic and transcriptomic approaches to address the active role of $\mathrm{GA}_{4}$ in Japanese apricot flower bud dormancy release. J. Exp. Bot. 64: 4953-4966.

Zhuang, W. B., T. Shi, Z. H. Gao, Z. Zhang and J. Y. Zhang. 2013 b. Differential expression of proteins associated with seasonal bud dormancy at four critical stages in Japanese apricot. Plant Biol. 15: 233-242. 